\title{
Original
}

\section{Usefulness of Stellate Ganglion Block for Severe Bell's Palsy : Earlier Performance Creates Better Outcome}

\author{
Hiroshi Takemura, Yutaka Masuda, Ryo Yatsushiro, Kenichiro OKamoto, \\ Norimasa Yamamoto and Akiyoshi Hosoyamada
}

\begin{abstract}
We evaluated stellate ganglion block (SGB) as the initial treatment for severe Bell's palsy. Twenty-nine patients with Bell's palsy who initially exhibited an electroneurographic ratio of less than $10 \%$ were divided into two groups: an immediate-treatment group, who underwent SGB within 3 days after symptoms first appeared, and a late-treatment group, who underwent SGB 4 or more days after symptoms first appeared. For the following 12 months the palsy score (Yanagihara's 40-point grading system) was measured and electroneurography was performed to assess recovery. Twelve months after onset, palsy scores in the two groups were similar. However, the electroneurographic ratio was significantly higher in the immediate-treatment group $(42.8 \pm 18.8 \%)$ than in the late-treatment group $(27.2 \pm 18.9 \% ; \mathrm{P}<0.05)$. Furthermore, the incidence of sequelae was significantly lower in the immediate-treatment group $(75.0 \%)$ than in the late-treatment group $(100 \% ; \mathrm{P}<0.05)$. These results suggest that earlier SGB did not affect symptomatic recovery but improved electrodiagnostic recovery and prevented sequelae. Because patients with Bell's palsy are always at a risk for more severe palsy with an electroneurographic ratio of less than $10 \%$, we suggest that SGB be performed in all patients as the initial treatment.
\end{abstract}

Key words: stellate ganglion block, initial treatment, severe Bell's palsy, electroneurography, sequelae

\section{Introduction}

Bell's palsy is an example of acute neuropathy. It is believed to occur because of a disturbance of microvascular circulation to facial nerve fibers due to viral infection or excessive sympathetic response ${ }^{1)}$. Local edema and ischemia lead to compression and hypoxia in the facial canal which exacerbate edema and ischemia ${ }^{2,3)}$. These conditions cause further degeneration of nerve fibers.

Patients with Bell's palsy whose minimal electroneurographic ratio, the ratio of the electroneurographic amplitude on the affected side to that on the unaffected side, is less than $10 \%$ have poor outcomes ${ }^{4,5)}$. Therefore, in the treatment of Bell's palsy, it is important in the initial stage to prevent such severe nerve degeneration. However, what treatment is most effective for patients with such severe Bell's palsy?

Most cases of Bell's palsy are treated with high-dose corticosteroids in combination with dextran and pentoxifylline, which have both anti-inflammatory and positive rheologic effects ${ }^{2}$. 
Table 1. Patient background

\begin{tabular}{|c|c|c|c|c|c|c|c|}
\hline \multirow{2}{*}{ Group } & \multirow{2}{*}{$\begin{array}{l}\text { Number of } \\
\text { patients }\end{array}$} & \multirow{2}{*}{$\underset{\text { (years) }}{\text { Age }}$} & \multirow{2}{*}{$\begin{array}{c}\text { Sex } \\
\text { (male/female) }\end{array}$} & \multicolumn{2}{|c|}{ Complications } & \multicolumn{2}{|c|}{$\begin{array}{c}\text { Corticosteroid } \\
\text { therapy }\end{array}$} \\
\hline & & & & $(+)$ & $(-)$ & $(+)$ & $(-)$ \\
\hline Immediate-treatment & 12 & $55.8 \pm 13.9$ & $4 / 8$ & 3 & 9 & $1 \mathrm{a}$ & 11 \\
\hline Late-treatment & 17 & $57.8 \pm 13.5$ & $10 / 7$ & 5 & 12 & 12 & 5 \\
\hline
\end{tabular}

Values are number of patients, and age is expressed as mean \pm standard deviation. a $\mathrm{P}<0.005$ vs. latetreatment group.

However, in severe Bell's palsy, results of infusion therapy are not always satisfactory.

Stellate ganglion block (SGB) has been often used as a treatment for Bell's palsy by pain clinicians in Japan. Treatment with SGB helps prevent degeneration of the facial nerve by inhibiting cervical sympathetic activity and increasing blood flow to the affected facial nerve $^{6)}$. Therefore, initial treatment with SGB in severe cases of Bell's palsy might lessen degeneration of the facial nerve and allow more complete recovery.

To determine whether earlier treatment with SGB is effective, we investigated long-term neurophysiologic recovery of patients with severe denervated Bell's palsy who underwent early or late SGB.

\section{Patients and Methods}

This study included 29 patients with Bell's palsy who initially had an electroneurographic ratio of less than $10 \%$ and were followed up for 12 months after onset of disease at Showa University Hospital Pain Clinic from December 1990 through October 1996. Patients were divided into two groups when first seen: an immediate-treatment group ( 12 patients), who visited our clinic within 3 days after symptoms first appeared (mean, 1.8 days after appearance), and a late-treatment group (17 patients), who visited the clinic 4 or more days after symptoms first appeared (mean, 17.1 days after appearance). The age and sex of patients and the incidence of other conditions, such as hypertension and diabetes, in the two groups were similar (Table 1).

Informed consent was obtained from each patient. Inpatients underwent SGB twice a day, and outpatients did so at least once a day for 1 month starting on the day of the first clinic visit, following our usual protocol. SGB was performed with $6 \mathrm{ml}$ of $1 \%$ mepivacaine via a paratracheal approach. We gradually decreased the frequency of SGB treatments after the 2 months: patients underwent SGB once a week from 6 months after onset until the end of the 12 th month.

For 12 months after symptoms first appeared, the palsy score (Yanagihara's 40-point grading system) was measured and electroneurography was performed to evaluate visible and electrophysiologic recovery.

Yanagihara's system consists of 10 facial expressions at rest and during voluntary movement of the forehead, eyelid, nostrils, and mouth. Scores range from 0 to 40 points; lower scores indicate more severe visible facial palsy. Electroneurography is useful to assess the degree of denervation because recorded amplitude indicates the level of activity of intact nerves $^{i)}$. Electroneurography was performed with a neurostimulator-recording apparatus (Neuropack MEM-3202 or Neuropack 2 MEM-7102, Nihon Kohden Co., Tokyo, Japan). 
Table 2. Changes in palsy score and incidence of sequelae 12 months after onset

\begin{tabular}{lcccc}
\hline \multicolumn{1}{c}{ Group } & Minimum & After 3 months & After 12 months & Incidence of sequelae \\
\hline Immediate-treatment & $1.8 \pm 1.8$ & $17.7 \pm 9.3^{\mathrm{a}}$ & $34.5 \pm 4.7^{\mathrm{a}}$ & $75^{\mathrm{b}}$ \\
Late-treatment & $2.6 \pm 2.7$ & $11.6 \pm 8.3^{\mathrm{a}}$ & $32.0 \pm 7.6^{\mathrm{a}}$ & 100 \\
\hline
\end{tabular}

Values are expressed as mean \pm standard deviation, and incidence of sequelae is expressed as percentage. a $\mathrm{P}<0.001$ vs. minimum. Palsy score did not significantly differ between groups. b $\mathrm{P}<0.05$ vs. late-treatment group.

Table 3. Changes in electroneurographic ratio

\begin{tabular}{cccc}
\hline Group & Minimum & After 3 months & After 12 months \\
\hline Immediate-treatment & $2.5 \pm 3.2$ & $8.6 \pm 11.6$ & $42.8 \pm 18.8 \mathrm{a}, \mathrm{b}$ \\
Late-treatment & $0.7 \pm 1.7$ & $4.5 \pm 8.9$ & $27.2 \pm 18.9 \mathrm{a}$ \\
\hline
\end{tabular}

Values are expressed as mean \pm standard deviation. a $\mathrm{P}<0.001$ vs. minimum. b $\mathrm{P}<0.05$ vs. latetreatment group.

Surface-type electrodes were used; the stimulator was placed near the stylomastoid foramen, and constriction of the orbicularis oris muscle was recorded. To assess the effectiveness of SGB treatment, we compared palsy scores and electroneurographic findings obtained 3 months and 12 months after onset.

In addition, we compared the incidence of sequelae, such as facial stiffness, synkinesis, crocodile tears, and postparalytic spasms, after 12 months between the treatment groups. Finally, we compared the cumulative number of SGB treatments performed within 12 months of onset to investigate how long SGB treatment should be continued.

Data are reported as mean \pm standard deviation. Student's $t$-test and the $\chi^{2}$ test were used to compare differences between the two groups. Differences with a $\mathbf{P}$ value $<0.05$ were considered statistically significant.

\section{Results}

Significantly more patients of the late-treatment group had received corticosteroids before consulting our clinic than had patients of the immediate-treatment group (12 of 17 patients, $70.6 \%$, vs. 1 of 12 patients, $8.3 \%$; Table 1 ).

Palsy scores at 3 and 12 months after onset were significantly higher than the lowest palsy scores in both groups (Table 2). In both groups the electroneurographic ratios at 3 months after onset did not differ significantly from the lowest ratios but those at 12 months after onset were significantly higher (Table 3 ). The palsy scores at 3 months and those at 12 months after onset did not differ significantly between groups (Table 2). However, 12 months after onset the electroneurographic ratio was significantly higher in the immediatetreatment group $(42.8 \pm 18.8 \%)$ than in the late-treatment group $(27.2 \pm 18.9 \%$; Table 3$)$.

The incidence of sequelae was significantly lower in the immediate-treatment group ( 9 of 12 patients, $75.0 \%$ ) than in the late-treatment group (all 17 patients, $100 \%$; Table 2).

The number of SGB treatments that had been performed by 4 months after onset was significantly higher in the immediate-treatment group than in the late-treatment group, par- 
Table 4. Cumulative SGB treatments performed within 12 months of onset

\begin{tabular}{lccccccc}
\hline \multirow{2}{*}{ Group } & 1 month & 2 months & 3 months & 4 months & 5 months & 6 months & 12 months \\
\cline { 2 - 7 } & & & & & & & \\
$\begin{array}{l}\text { Immediate- } \\
\text { treatment }\end{array}$ & $31.3 \pm 8.3^{\mathrm{a}}$ & $49.4 \pm 15.6^{\mathrm{b}}$ & $59.2 \pm 19.2^{\mathrm{c}}$ & $65.2 \pm 20.9 \mathrm{c}$ & $70.8 \pm 23.5$ & $74.8 \pm 25.1$ & $88.2 \pm 30.5$ \\
$\begin{array}{l}\text { Late- } \\
\text { treatment }\end{array}$ & $15.5 \pm 11.4$ & $31.8 \pm 15.7$ & $41.4 \pm 16.6$ & $49.3 \pm 17.9$ & $55.6 \pm 18.9$ & $59.6 \pm 20.1$ & $72.9 \pm 26.2$ \\
\hline
\end{tabular}

SGB, stellate ganglion block. Values are number of SGB treatments expressed as mean \pm standard deviation. a $\mathrm{P}<0.001$, b $\mathrm{P}<0.01$, c $\mathrm{P}<0.05$ vs. late-treatment group.

ticularly during the 1 st month (Table 4). However, from 5 to 12 months, the total number of treatments performed did not differ between the groups (Table 4).

\section{Discussion}

Although recovery is spontaneous in most cases of Bell's palsy ${ }^{1,8}$, the efficacy of various treatments has been recognized. It is ethically impossible to perform placebo-controlled studies of patients with Bell's palsy. For this reason, some clinicians who are not anesthesiologists are likely to doubt the efficacy of SGB for Bell's palsy. Furthermore, such mild cases of Bells' palsy should be excluded from studies evaluating therapeutic efficacy. Therefore, we chose as our subjects patients whose minimal electroneurographic ratios were less than $10 \%$ and who were not expected to recover spontaneously.

This study compared patients who mainly underwent immediate SGB treatment after onset with those who underwent supplementary or late SGB treatment. Many patients with severe Bell's palsy who did not immediately undergo SGB were first treated with systemic corticosteroids. We think this tendency is due to the success of Stennert's method, which is reported to bring good results and does not require technical skill. However, although immediate SGB treatment was equal to initial corticosteroid therapy before late SGB treatment in terms of visible clinical recovery, it resulted in greater electrodiagnostic recovery.

The most commonly used drugs do not seem able to prevent sequelae in spite of both anti-inflammatory and positive rheologic effects. In contrast, SGB has no anti-inflammatory effects but rapidly and effectively induces vasodilation by inhibiting cervical sympathetic activity and redistributes blood flow between the unaffected and affected sides. Treatment with SGB increases blood flow through the nutrient arteries of the affected facial nerve ${ }^{9}$. Evidence that earlier SGB prevents sequelae from developing in some patients with severe Bell's palsy also suggests that earlier SGB might prevent further degeneration in the initial stage of severe Bell's palsy and stimulate appropriate regeneration of damaged axons in the endoneural tube. Furthermore, treatment with SGB is also safer for patients who have diabetes or peptic ulcer or patients who are pregnant. Therefore, immediate SGB seems to be more beneficial than corticosteroid therapy.

As the cumulative number of SGB treatments indicate, to achieve the benefits of greater electrodiagnostic improvement and fewer sequelae, initial SGB treatment must be started within 3 days after onset of symptoms and continued for 4 months. If the facial nerve is injured in the facial canal, the distance between the site of injury and the region of dener- 
vated muscle is approximately $140 \mathrm{~mm}$. At an axonal growth rate of $1 \mathrm{~mm}$ per day, 140 days would be required to regenerate a fiber of the facial nerve ${ }^{10)}$. Therefore, SGB treatment should be continued for at least this long to increase blood flow, which is indispensable for regeneration of the affected facial nerve fiber.

Electroneurography, nerve excitability tests, and maximal stimulation tests yield little useful information in the first 3 to 4 days $^{2)}$. Accordingly, we cannot predict which patients with Bell's palsy are at risk for more severe palsy, as indicated by an initial electroneurographic ratio of less than $10 \%$. The most important goal of initial treatment is to stop progressive damage as soon as possible, before such severe degeneration has occurred. Also, it is important to perform more beneficial treatment that stimulates regeneration of the severely damaged nerve.

In summary, this study has shown that earlier SGB is effective as the initial treatment for cases of Bell's palsy with severe denervation. We suggest that SGB be begun immediately after the appearance of symptoms in all cases of Bell's palsy.

\section{References}

1) Moldaver J: The problem of Bell's palsy: Etiology and analysis of therapeutic approach. In: The Facial Palsies, Moldaver J and Conley J (Eds), Charles C Thomas, Springfield, IL, pp 65-73 (1980)

2) Stennert E: New concepts in the treatment of Bell's palsy. In: Disorders of the Facial Nerve, Graham MD and House WF (Eds), Raven Press, New York, pp 313-318 (1982)

3) Sunderlund S: Some anatomical and pathophysiological data relevant to facial nerve injury and repair. In: Facial Nerve Surgery, Fisch U (Ed), Aesculapius Pub., Birmingham, AL, pp 47-61 (1977)

4) May M, Podvinec M, Ulrich J, Peiterson E and Klein SR: Idiopathic (Bell's) palsy, herpes zoster cephalicus and other facial nerve disorders of viral origin. In: The Facial Nerve, May M (Ed), Thieme, New York, pp 365-399 (1986)

5) Yasukawa M, Yasukawa $\mathrm{K}$ and Ohnuma H: Prognostic diagnosis of facial palsy with electroneuronography. Masui, 44: 378-387 (1995) (in Japanese)

6) Korkis FB: Treatment of recent Bell's palsy by cervical sympathetic block. Lancet, I: 255-257 (1961)

7) Esslen E: Electromyography and electroneurography. In: Facial Nerve Surgery, Fisch U (Ed), Aesculapius Pub., Birmingham, AL, pp 93-100 (1977)

8) Peitersen E: Natural history of Bell's palsy. Acta Otolaryngol Suppl, 492: 122-124 (1992)

9) Murakawa $K$, Ishimoto $E$, Noma $K$, Ishida $K$, Nishijima $M$ and Izumi $R$ : Circulatory effects of stellate ganglion block in idiopathic facial palsy. Masui, 43: 356-360 (1994) (in Japanese)

10) May M: Microanatomy and pathophysiology of the facial nerve. In: The Facial Nerve, May M (Ed), Thieme, New York, pp 63-74 (1986) 